\title{
The Potential Use of a Cold Atmospheric Plasma Jet for Decontamination of Hospital Surfaces. A Pilot Study
}

\author{
Muireann Fallon, ${ }^{\mathrm{a}, *}$ Sarah Kennedy, ${ }^{\mathrm{a}}$ Sharath Kumar, ${ }^{\mathrm{b}}$ Stephen Daniels, ${ }^{\mathrm{c}}$ \& \\ Hilary Humphreys ${ }^{\mathrm{a}, \mathrm{d}}$ \\ aDepartment of Clinical Microbiology, Royal College of Surgeons in Ireland, Beaumont \\ Hospital, Dublin, Ireland; 'Intel Corporation Ireland, Collinstown Industrial Estate, Leixlip, Co \\ Kildare, Republic of Ireland; 'National Centre for Plasma Science and Technology, Dublin City \\ University, Dublin, Ireland; dDepartment of Microbiology, Beaumont Hospital, Dublin, Ireland
}

*Address all correspondence to: Muireann Fallon, Department of Clinical Microbiology, Royal College of Surgeons in Ireland, Beaumont Hospital, Dublin, Ireland; Tel.: +3531-809-3715, E-mail: MuireannFallon@rcsi.ie

\begin{abstract}
Hospital surfaces are a source of potential infection due to contamination by microorganisms such as bacteria and viruses. Bacterial biofilms are of particular importance, due to their persistence in the hospital environment. Cold atmospheric pressure plasma (CAPP) is a novel potential method of hospital surface decontamination. In this study, we aimed to show the potential use of a CAPP jet for hospital decontamination. Bacterial biofilms were grown on common hospital surface materials and treated with an air-driven CAPP jet. Viable bacteria in treated biofilms were measured. Confocal microscopy and staining were used to gather images of CAPP-treated biofilms. The effect of CAPP inactivation was also assessed alongside the use of a detergent. CAPP inactivated clinically relevant bacteria both in planktonic and biofilm structures. A 90 s CAPP treatment led to an average of $82 \%$ decrease in Escherichia coli (E. coli) and $70 \%$ decrease in methicillin-resistant Staphylococcus aureus (MRSA) biofilm viability grown on polysterene. Confocal microscopy was used to confirm CAPP-induced inactivation of bacterial cells within mature growth on glass. CAPP treatment was also compared to treatment with detergent commonly used in hospitals. It was found that biofilm inactivation was greatest when treated with both detergent and CAPP. When in combination with detergent, viability of E. coli and MRSA biofilms grown on polysterene were decreased by $97 \%$ and $94 \%$, respectively. A CAPP jet was shown to inactivate biofilms on hospital surfaces, particularly when used alongside detergent. This may suggest a role for CAPP in hospital decontamination.
\end{abstract}

KEY WORDS: nonthermal plasma, disinfection, biofilm

\section{INTRODUCTION}

Healthcare-associated infections (HAIs) occur due to admission to, or contact with a healthcare facility such as a hospital, nursing home, or health clinic. HAIs are thought to be the most common complication affecting hospitalized patients worldwide. HAIs are associated with increased length of hospital stay, morbidity, mortality, and financial cost. $^{1,2}$

HAIs can be caused by viruses, bacteria, or fungi. A study conducted by European Centre for Disease Prevention and Control (ECDC) found the most common pathogenic organisms isolated in HAIs were Escherichia coli (E. coli), Staphylococcus aureus ( $S$. 
aureus), Pseudomonas aeruginosa (P. aeruginosa), Klebsiella spp., and Clostridioides difficile ( $C$. difficile). Staphylococcus aureus was the most prevalent in bloodstream infection, while E. coli were commonly found to cause urinary tract infections. ${ }^{3}$

HAIs can be caused by pathogens, such as bacteria or viruses, on the hands of healthcare workers (HCWs) or in the environment surrounding the patient. ${ }^{4}$ Contaminated surfaces in healthcare settings are a reservoir for HAI and the decontamination of surfaces is crucial in the prevention of infection.

Enhanced cleaning procedures lessen the microbial contamination of hospital surfaces and decrease the acquisition of infection. A study by Rutala et al., ${ }^{5}$ showed that enhanced cleaning of 9 hospitals by additional cleaning agents or decontamination devices led to a significant decrease in bacteria found on surfaces. Dancer et al. ${ }^{6}$ also showed that enhanced cleaning reduced multidrug-resistant organism (MDRO, e.g., methicillin-resistant $S$. aureus [MRSA]) contamination on surfaces. By adding an additional member of cleaning staff to a hospital ward, it was found that MRSA contamination of high-touch areas was reduced by $33 \%$ and MRSA infection fell by $27 \%$.

The surfaces most likely to be contaminated tend to be those that are either touched most frequently, or those nearest the patient. These are surfaces such as bed-rails, bed-tables, mattresses, door handles, or portable medical equipment. ${ }^{7-10}$ Hospital surfaces can play a part in the spread of HAIs and enhanced decontamination of these surfaces can lead to decreased infection within hospitals. ${ }^{11}$

Bacteria that cause HAI can often survive in the hospital environment for long periods of time. Numerous studies have shown persistence of microorganisms for weeks or months despite enhanced cleaning procedures. ${ }^{12,13}$ Esteves et al. ${ }^{14}$ showed that E. coli could survive on the hospital floor and mattress for over 3 weeks. Staphylococcus aureus remained viable on these surfaces for over 70 days. This study also showed that bacteria could survive for longer periods with the addition of soil (e.g., blood, bodily secretions, or protein) on surfaces. This highlights the importance of not only disinfecting surfaces but also cleaning for the removal of dirt or soil.

One way in which bacteria can survive on surfaces is the formation of biofilms, which are aggregates or clumps of microbial cells often coated in a slime-like matrix. Bacteria within biofilms can differ from single-cell, planktonic bacterial with altered tolerance to antibiotics and cleaning agents. ${ }^{15,16}$ Over $90 \%$ of dry surfaces in hospital wards can be contaminated with bacterial biofilms. ${ }^{17,18}$ These biofilms can be found in the near-patient environment, such as on mattresses, or further away from patients, including telephones at nursing stations. Biofilms can confer a higher resistance to biocides than planktonic cells. ${ }^{17}$

Almatroudi et al. ${ }^{16}$ showed that $S$. aureus biofilms were significantly more resistant to inactivation by hypochlorite disinfection than planktonic cells.

Biofilms on hospital surfaces can aid in the persistence of bacteria in the environment and ultimately contribute to the spread of HAIs. Hospital decontamination methods should, therefore, consider the inactivation of bacteria both in planktonic and biofilm states.

Current cleaning and decontamination methods used in healthcare settings have several drawbacks. Alongside the necessary cleaning of hospital surfaces to remove dirt 
and biological soil by detergents, disinfectants and devices may be used to enhance the decontamination of the environment. Some decontamination technologies have been developed, such as hydrogen peroxide and ultraviolet (UV) radiation devices, for enhanced terminal cleaning. ${ }^{19,20}$ These, however, require the emptying of clinical areas of patients, staff, and sometimes removal of furnishings, and this downtime is often not practical in a hospital setting.

Applications of plasma and in particular non-thermal or low temperature plasma devices are a burgeoning field of research. Cold atmospheric pressure plasma (CAPP) systems may have a potential role as a hospital decontamination tool. Microorganisms are inactivated by CAPP due to the local production of a cocktail of reactive oxygen species (ROS), reactive nitrogen species (RNS) and possibly the production of UV light. ${ }^{21,22}$ Increased ROS and RNS production by CAPP have been shown to lead to greater bactericidal effects. ${ }^{23,24}$ ROS can lead to bacterial inactivation through the oxidation of bacterial amino acids, DNA damage, and membrane proliferation. ${ }^{25,26}$ RNS also have an effect on the bacterial cell. RNS such as nitric oxide can cause bacterial DNA strand breaks through deamination of nucleobases and the destruction of protein iron clusters. ${ }^{27}$

CAPP is able to inactivate a wide range of microbes, including fungi, viruses, and bacteria. ${ }^{28-31}$ CAPP can also inactivate bacteria within biofilms structures, ${ }^{32,33}$ which is crucial for decontamination of hospital surfaces. Plasma is a "dry" technology that could be useful in the decontamination of soft surfaces and may, with appropriate precautions, be used in the presence of patients and staff. ${ }^{34}$ CAPP devices for hospital decontamination and biofilm control have been extensively reviewed in previous articles. ${ }^{35,36} \mathrm{~A}$ handheld CAPP device has potential as a useful device for decontamination of hospital surfaces and to limit the spread of HAIs.

In this study, we investigated the decontamination ability of an air-driven, single nozzle CAPP jet against clinically relevant bacteria, which often cause HAIs, both in planktonic and biofilm form, and we assessed its efficacy with a conventional disinfectant.

\section{METHODS}

\section{A. Bacterial Strains}

Two bacterial strains were used in this study; E. coli BH 22 and S. aureus BH1CC. Both are clinical isolates collected from Beaumont Hospital, an 820-bed tertiary care center containing the national neurosurgical and renal transplantation units for the Republic of Ireland. BH 22 is an extended-spectrum betalactamase producing antibiotic-resistant $E$. coli isolate. BH1CC is an antibiotic-resistant, MRSA isolate.

\section{B. Biofilm Formation}

Overnight growth of bacteria in Mueller-Hinton (MH) broth (CM0405; Oxoid) was diluted to approximately $1 \times 10^{7} \mathrm{CFU} / \mathrm{mL}$ in $\mathrm{MH}$. Bacterial dilution was used to cover 
the intended surface on which the biofilm should attach. Various surfaces commonly used in hospitals were selected as a representation of the clinical environment. The surfaces and volumes needed to cover each surface coupon are indicated in Table 1. The surfaces inoculated with bacteria were incubated statically overnight at $37^{\circ} \mathrm{C}$. Media were removed after 24 hours and replaced with fresh, sterile media. Biofilms were incubated for a further 24 or 48 hours. After biofilm growth, unattached cells were removed through washing with sterile $1 \mathrm{X}$ phosphate buffered saline (PBS; Sigma Aldrich, Ireland). Excess liquid was removed by drying the surface in a laminar airflow cabinet for 30 minutes.

\section{CAPP System}

The CAPP device used has been previously described. ${ }^{37}$ The device consisted of a single plasma jet constructed from an $11 \mathrm{~cm}$ long cylinder that includes a stainless-steel pin, which acts as the powered electrode, and an outer grounded electrode. The power supply used on the system is capable of delivering voltages of approximately $30 \mathrm{kV}$ at $21-23$ $\mathrm{kHz}$. An air compressor delivers a gas supply of ambient air at 6 to 12 standard liters per minute (SLM) (Fig. 1).

A

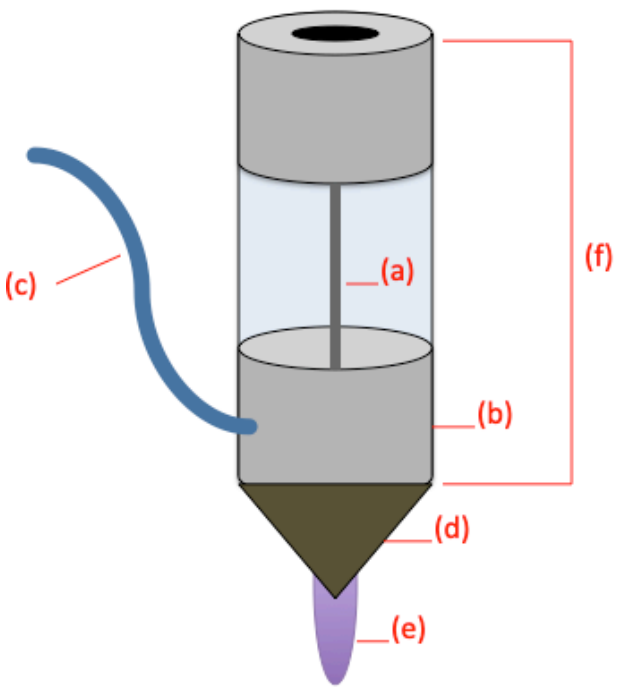

B

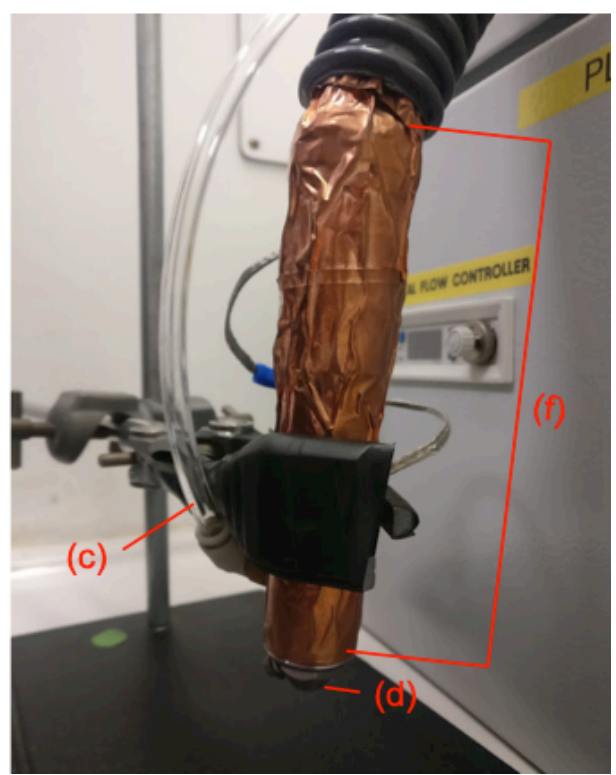

FIG. 1: CAPP System. (A) A simple schematic diagram of the CAPP system, (B) image of CAPP system. Within figure: (a) electrode pin, (b) grounding electrode, (c) air flow supply tube, (d) nozzle, (e) plasma plume, (f) jet cylinder. 
TABLE 1: Surfaces for biofilm growth. The following surfaces were used for the growth of biofilms

\begin{tabular}{|l|c|c|}
\hline \multicolumn{1}{|c|}{ Surface } & Size $\left(\mathbf{m m}^{2}\right) /$ diameter $(\mathbf{m m})$ & Volume of media/stain $(\boldsymbol{\mu L})$ \\
\hline 96-well plates (polystyrene) & $($ Well surface) $7 \mathrm{~mm}$ & 100 \\
\hline Pegs (polystyrene) & $7 \mathrm{~mm}$ & 100 \\
\hline Stainless steel coupon (steel) & $20 \mathrm{~mm}$ & 1500 \\
\hline $\begin{array}{l}\text { Powder coated steel coupon } \\
\text { (steel)* }\end{array}$ & $20 \mathrm{~mm}$ & 1500 \\
\hline $\begin{array}{l}\text { Flooring coupon } \\
\text { (linoleum)** }\end{array}$ & $20 \mathrm{~mm}$ & 1500 \\
\hline Glass cover slip (borosilicate) & $484 \mathrm{~mm}^{2}$ & 3000 \\
\hline
\end{tabular}

The volume of bacterial culture needed for each surface is given (UV, ultraviolet light). *Powder-coated steel refers to steel which has been coated in a powder and prevents corrosion. $* *$ The surface of flooring coupons is coated in polyvinyl chloride.

\section{CAPP Treatment}

Samples or surfaces were treated at a distance of $1.5 \mathrm{~cm}$ from the nozzle of the jet for 30 or $90 \mathrm{~s}$. The jet was static during CAP treatment. As a negative control, the power source of the plasma system was switched off and the gas allowed to pass through the nozzle of the jet without sparking a plasma.

\section{E. Zone of Inhibition}

Overnight cultures of bacteria were diluted to 0.5 OD (approx. $1 \times 10^{7} \mathrm{cfu} / \mathrm{mL}$ ) in PBS. The diluted culture was spread evenly across a $\mathrm{MH}$ agar plate using a sterile cotton swab (Sparks, Ireland). A mark was made on the bottom of the plate as a target and the plate was treated directly with CAPP at a distance of $1.5 \mathrm{~cm}$. Positive untreated controls of bacteria were plated and not exposed to CAPP or were exposed to gas flow only. Negative controls were sterile agar plates treated with gas only but not CAPP, or plates left untreated.

All plates were incubated statically overnight at $37^{\circ} \mathrm{C}$. The plates were then examined for inhibition of growth compared to the untreated positive control plate. The diameter of the zone of inhibition was visually inspected and measured from the widest possible point on each plate. This was performed at least 3 times and in duplicate. The mean zone of inhibition was graphed \pm standard deviation (SD).

\section{F. Bacterial Viability Assays}

Biofilm viability on the surfaces listed above (Table 1) was analyzed using resazurin solution (Sigma Aldrich, Ireland). Biofilms formed on coupons were removed by placing each coupon in universal tubes containing $5 \mathrm{~mL}$ of sterile PBS, then sonicated for 5

Volume 11, Issue 1, 2021 
min and vortexed for 30 s. $100 \mu \mathrm{L}$ of the resulting effluent was incubated with $100 \mu \mathrm{L}$ of resazurin solution (in $\mathrm{MH}$ broth) with a final concentration of $88 \mu \mathrm{M}$ resazurin in a 96-well polystyrene plate (Nunc, Denmark). The plate was incubated in the dark at $37^{\circ} \mathrm{C}$ for 1 hour.

Biofilms grown on 96-well plates, pegs, or glass cover slips (Table 1) were incubated directly with resazurin solution $(88 \mu \mathrm{M}$ in $\mathrm{MH})$ and incubated in the dark at $37^{\circ} \mathrm{C}$, shaking. $200 \mu \mathrm{L}$ of the resazurin solution surrounding the surface was placed into a 96well polystyrene plate.

Biofilm viability was determined using a fluorimeter with an excitation at 544 $\mathrm{nm}$ and an emission value of $590 \mathrm{~nm}$ (Victor X3 2030 Multibel Reader, Perkin Elmer, Ireland). Each experiment was performed in triplicate 3 times, and the results represent percentage change of mean fluorescent intensity $\pm \mathrm{SD}$ compared to positive control, which was taken to be $100 \%$.

\section{G. Confocal Scanning Laser Microscopy}

Biofilms were grown for 24, 48, or 72 hours on glass and treated with CAPP for $90 \mathrm{~s}$. Glass was chosen as a pilot surface as it is a material found in hospitals, and being transparent, it allowed for more accurate confocal microscopy images to be captured. Positive controls were exposed to gas flow only also for $90 \mathrm{~s}$. Biofilms were stained using the LIVE/DEAD ${ }^{\mathrm{TM}}$ BacLight ${ }^{\mathrm{TM}}$ Bacterial Viability Kit (Thermo Fisher, UK) as per kit instructions.

Images of the biofilms stained with the viability kit were captured using a confocal scanning laser microscopy (Olympus Fluoview FV1000 laser scanning biological microscope, Mason Technologies, Dublin) following CAPP treatment. At least 3 images of each biofilm were captured, ensuring that they were most representative of the whole biofilm. Digital images and z-stacks were collected and examples are shown in the results section. The relative amount of green $\left(\mathrm{SYTO}^{\circledR} 9\right)$ and red (propidium iodide) fluorescence in each image was quantified using image-J software. SYTO ${ }^{\circledR} 9$ stains all cells regardless of membrane damage, creating an overall green color. Propidium iodide can only penetrate bacterial cells with membrane damage and so labels damaged or inactivated cells with a red color. This allows the measurement of relative "live" membrane intact cells and "dead" membrane damage cells percentages per image.

\section{H. Cleaning Assay}

Bacterial biofilms were formed on polystyrene pegs as described above. Biofilms were treated with CAPP for $90 \mathrm{~s}$, covered in a 1000 ppm hypochlorite and Teepol ${ }^{\circledR}$ (Teepol, UK) cleaning solution for $90 \mathrm{~s}$ or treated with both CAPP and then cleaning solution. Bacterial viability was then determined through resazurin assays. Assays were performed at least in triplicate, 3 times, and the results represent percentage change of mean fluorescent intensity \pm SD compared to positive control, which was taken to be $100 \%$. 


\section{Statistical Analysis}

All statistical analysis was performed using Prism Statistical Software (version 8.3.0, GraphPad, USA). Multiple comparisons of samples groups using ordinary one-way ANOVA tests were used. $P$-values of $<0.05$ were considered significant and are denoted in results by a star symbol (*).

\section{RESULTS}

\section{A. Planktonic Bacterial Inactivation}

To determine the antimicrobial effect of CAPP against clinically relevant bacteria, zones of inhibition assays were performed. Exposure of each bacterial strain to CAPP for either 30 or $90 \mathrm{~s}$ produced a zone of no growth or inhibition. The zone of inhibition was measured visually, and a sample of images is shown in Fig. 2A. The diameter of zones of inhibition for each bacterial strain was measured and the average mean of each is shown with standard deviations (SD) (Fig. 2B). For each strain, $90 \mathrm{~s}$ treatments produced a larger zone of inhibition than $30 \mathrm{~s}$. The largest zones of inhibition were observed after $90 \mathrm{~s}$ treatment of $E$. coli $(4.2 \mathrm{~cm})$ and the smallest zone of inhibition was seen after $30 \mathrm{~s}$ treatment of MRSA $(1.9 \mathrm{~cm})$.

\section{B. Biofilm Viability on Hospital Surfaces After Capp Treatment}

E. coli and MRSA biofilms were grown on hospital surfaces for 48 hours. After CAPP treatment, viability decreased for both bacteria on all surfaces (Fig. 3). The greatest decrease after CAPP treatment was seen in biofilms grown on polystyrene with $18 \%$ and $30 \%$ of $E$. coli and MRSA bacteria in biofilm, respectively, remaining viable. After CAPP treatment, $E$. coli viability was $56 \%, 47 \%, 34 \%$, and $59 \%$ on stainless steel, powder coated steel, glass, and linoleum, respectively. MRSA viability was 56\%, 70\%, 48\%, and $30 \%$, respectively, on these surfaces. For each treated surface, there was a greater reduction in viability seen with $E$. coli biofilms than with MRSA.

Oxidizing agents, such as the reactive species produced by CAPP, can produce membrane damage in bacteria. ${ }^{21}$ To assess inactivation through membrane damage induced by CAPP treatment, biofilms were dyed with SYTO 9 and propidium iodide (PI), and imaged using confocal microscopy. E. coli and MRSA were grown on glass for 24, 48 , or 72 hours and treated with CAPP for 90 s (Figs. 4 and 5).

E. coli biofilms grown on glass for 24,48 , or 72 hours had a majority of bacterial cells with intact membranes. This is seen with a majority of green cells to be seen in confocal images (Fig. 4) and this was quantified as the percentage of green fluorescence in confocal images of untreated 24,48 , and 72 -hour biofilms is $48 \%, 60 \%$, and $71 \%$, respectively. In CAPP-treated E. coli biofilms, the percentage of undamaged cell membranes was lower with $41 \%, 47 \%$, and $23 \%$ found in 24,48 and 72 -hour biofilms, respectively. 
A

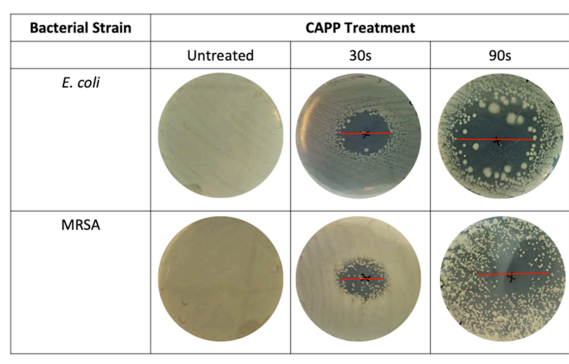

B

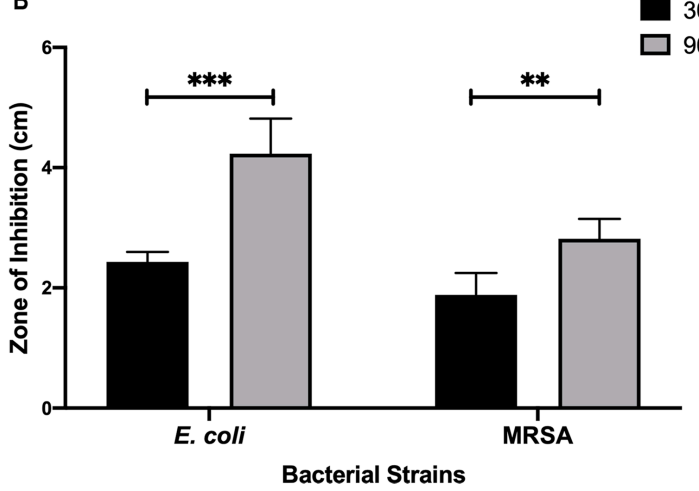

FIG. 2: Zone of inhibition of clinically relevant bacteria. S. aureus BH48 (MRSA), E. coli BH 25922 (E. coli) were lawned on MH agar and treated with CAPP for 30 or $90 \mathrm{~s}$ and incubated overnight at $37^{\circ} \mathrm{C}$. (A) The image shows images of the treated plates. Red or horizontal lines indicate the diameter of zones of inhibition. (B) The diameter of the zone of inhibition was measured at its widest point. Mean diameters of zone of inhibition are shown above $\pm \mathrm{SD}(* * P \leq 0.01, * * * P \leq 0.001)$.

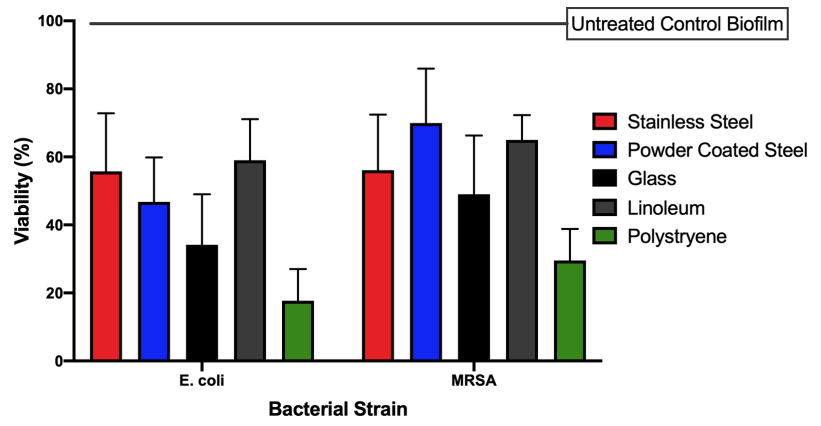

FIG. 3: Bacterial viability of CAPP treated biofilms grown on hospital surfaces. 48 hour biofilms of $E$. coli and MRSA were grown on various hospital surface materials. Biofilms were treated with CAPP for $90 \mathrm{~s}$ and the resulting bacterial viability was evaluated using resazurin conversion assays. The resulting viability is represented as a percentage of an untreated positive control biofilm, which is taken as $100 \%$ viability. The graph shows the mean percentage \pm SD. 


\section{A}
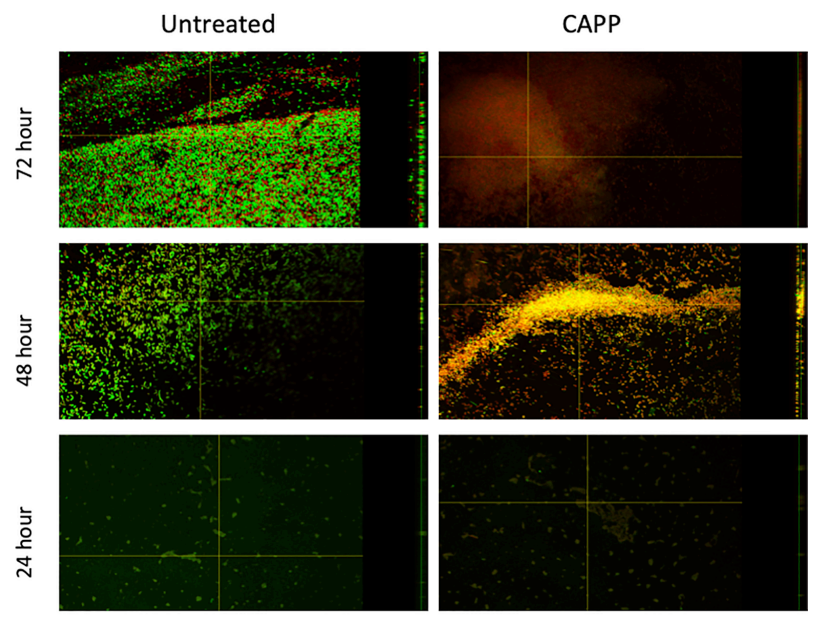

\section{B}

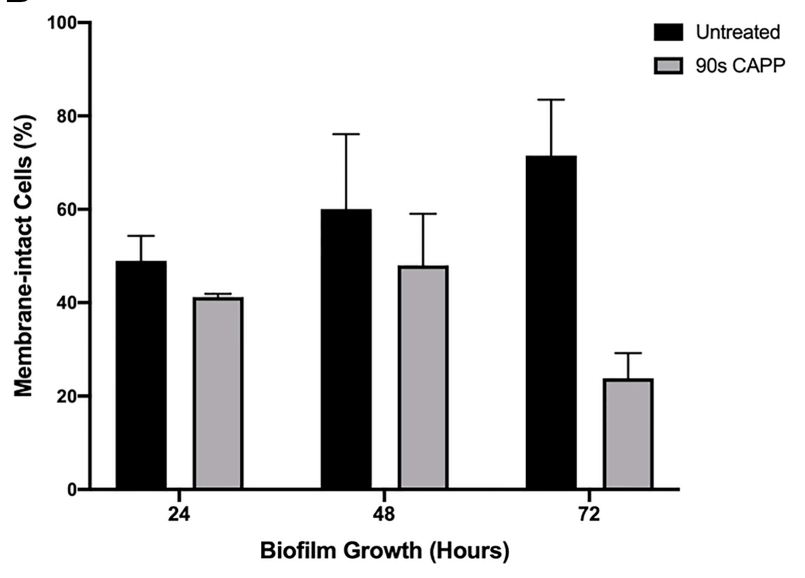

FIG. 4: Confocal scanning electron microscopy images of CAPP-treated E. coli biofilms. 48 hour biofilms of E. coli were treated with CAPP for $90 \mathrm{~s}$. Biofilms were stained with BacLight LIVE/DEAD stain consisting of 2 dyes; Styo9, which stains all cells green, and propidium iodide, which stains membrane-damaged cells red. This allows undamaged cells to appear green and membrane damaged cells to appear red. Images are representative of at least 3 fields of view of each biofilm with a $40 \mathrm{X}$ oil objective lens. (A) Sample of confocal images. (B) Percentage of green or "intact" cells in biofilms.

Increased bacterial membrane damage is also seen in CAPP-treated MRSA biofilms (Fig. 5). Confocal images of untreated MRSA biofilms revealed few undamaged bacterial cells as indicated by the green image (Fig. 5A). This was quantified as $43 \%$, $43 \%$, and $56 \%$ undamaged bacterial cells in untreated MRSA biofilms grown for 24 , 48, and 72 hours, respectively (Fig. 5B). In CAPP-treated MRSA biofilm, less green, 
A
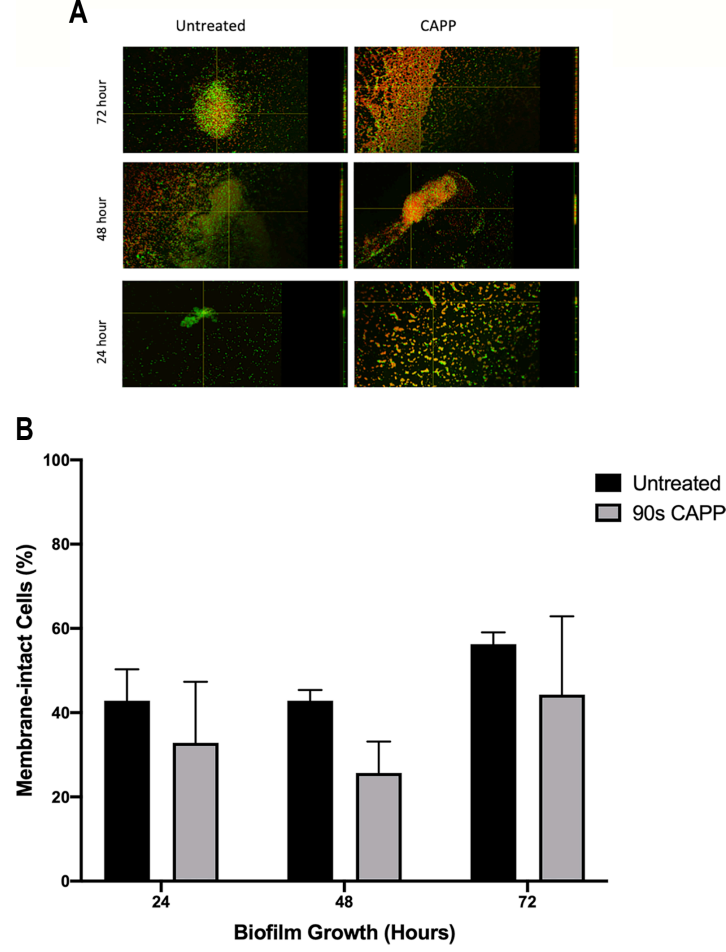

FIG. 5: Confocal scanning electron microscopy images of CAPP-treated MRSA biofilms. 48 hour biofilms of MRSA were treated with CAPP for $90 \mathrm{~s}$. Biofilms were stained with BacLight LIVE/DEAD stain consisting of 2 dyes; Styo9 which stains all cells green and propidium iodide which stains membrane damaged cells red. This allows undamaged cells to appear green and membrane damaged cells to appear red. Images are representative of at least 3 fields of view of each biofilm with a $40 \mathrm{X}$ oil objective lens. (A) Sample of confocal images. (B) Percentage of green or "intact" cells in biofilms.

undamaged cells (red) and membrane-damaged cells (green) can be seen visually (Fig. 5A). Membrane intact cells in confocal images of CAPP-treated MRSA biofilms are quantified as $14 \%, 7 \%$ and $18 \%$ in 24, 48 and 72 -hour biofilms, respectively (Fig. 5B).

\section{CAPP as a Decontamination Tool Alongside Cleaning}

In healthcare settings, routine cleaning is also necessary for the removal of dirt and biological soil alongside any additional decontamination procedure for the inactivation of microorganisms. To investigate the use of CAPP alongside normal hospital cleaning, we assessed the bacterial viability of $E$. coli and MRSA biofilms after treatment with CAPP, a cleaning solution or both (Fig. 6).

Both CAPP and routine cleaning alone resulted in bacterial inactivation within $E$. coli $(9.5 \%$ and $3.4 \%$ remaining viable, respectively) and MRSA (39.8\% and 9.8\%) 


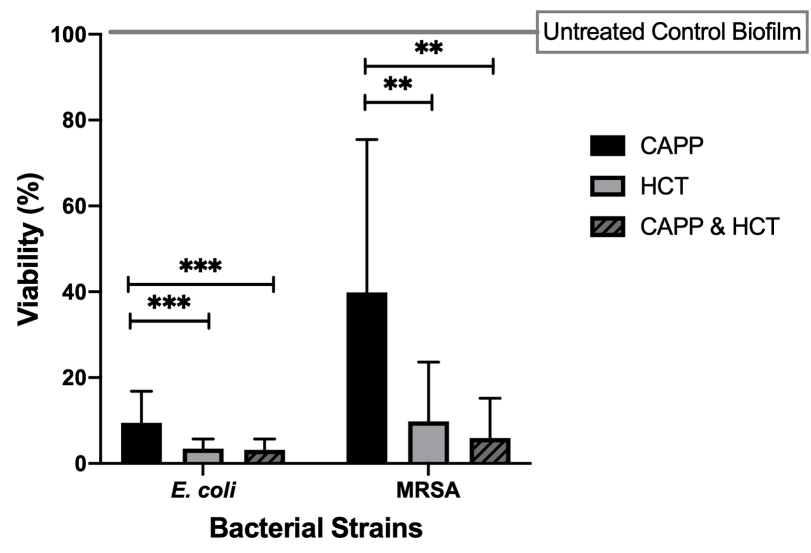

FIG. 6: Bacterial viability of CAPP and hypochlorite treated biofilms. 48-hour biofilms of $E$. coli and MRSA were grown on polystyrene pegs and treated with CAPP, a hypochlorite and Teepol cleaning solution (HCT) or both for $90 \mathrm{~s}$ and the resulting bacterial viability was evaluated using resazurin conversion assays. The resulting viability is represented as a percentage of an untreated positive control biofilm, which is taken as $100 \%$ viability. The graph shows the mean percentage $\pm \mathrm{SD}(* * P \leq 0.01, * * * P \leq 0.001)$.

biofilms. However, the greatest bacterial inactivation was seen when CAPP and cleaning solution were utilised in combination After both CAPP and cleaning solution treatment, $3.2 \%$ of E. coli and $5.9 \%$ of MRSA within biofilms remained viable.

\section{DISCUSSION}

Hospital-acquired infections are a global concern causing a vast number of deaths, increasing lengths of hospital stay, and a great cost to healthcare systems. ${ }^{1}$ Current cleaning practices often do not remove microbial contamination, particularly biofilms on hospital surfaces ${ }^{38}$ A possible new decontamination tool could be the use of CAPP devices, in addition to routine hygiene measures. We assessed the antimicrobial action of a CAPP device against 2 common and clinically relevant bacteria that cause HAI, in both a planktonic and in a biofilm state, and we evaluated the use of a CAPP device under hospital conditions.

A single jet, air-driven CAPP device was chosen to investigate the possible role for plasma devices in decontamination of surfaces. Using atmospheric air as a gas source can allow for a low-cost solution for decontamination. A plasma jet configuration also has the benefit of being portable as well as allowing for decontamination of irregularly shaped equipment. Plasma has the advantage of being a "dry" decontamination tool, which allows for eradication of microbes on surfaces that are not suitable for liquid detergents, such as soft furnishings. Current technologies used in hospital decontamination include UV and hydrogen peroxide devices. ${ }^{20}$

Volume 11, Issue 1, 2021 
However, these technologies require hospital rooms to be emptied of patients and staff, which can be particularly difficult in the busy healthcare environment. ${ }^{11,39}$ Plasma has an advantage as it can potentially be used safely while patients and HCWs remain in the room, if the gaseous emissions from the plasma, such as ozone, are correctly managed.

Ozone is produced by CAPP devices and is thought to contribute to antimicrobial action. ${ }^{40}$ Ozone-producing devices are used for hospital decontamination in sealed environments. ${ }^{41}$ However, ozone is also toxic and can cause pulmonary side effects. A workplace exposure limit of 0.2 parts per million of ozone in air over a 15-minute exposure time has been suggested as a safe working limit. ${ }^{41,42}$ For use in hospital decontamination, CAPP devices should balance the concentration of antimicrobial potential of the device while not emitting dangerous levels of gases such as ozone. Due to the air velocity used in CAPP jets, the potential spread of bacteria across surfaces during treatment should be considered. Adding a post CAPP treatment cleaning step, such as wiping the surface with a disinfectant wipe, could negate this issue. ${ }^{43}$

The clinically relevant $E$. coli and MRSA isolates in planktonic state were killed after exposure to CAPP. CAPP treatment led to a zone of inhibition on agar plates lawned with bacteria. Increasing exposure time from $30 \mathrm{~s}$ to $90 \mathrm{~s}$ also increased the zone of inhibition or the number of bacteria killed. Time-dependant inhibition zone size was observed previously. Mahasneh et al ${ }^{44}$ also showed increased zones of inhibition with increased treatment time using a pulsed, helium driven CAPP jet.

The diameter of inhibition zones also differed between the 2 bacteria; there was greater inactivation of E. coli compared to MRSA. This is seen elsewhere in decontamination studies due to differences in outer cell wall composition and the shape of the bacterium accounting for differences in anti-bacterial efficiency. ${ }^{45}$ Often the permeability of the bacterial cell can lead to intrinsic resistance to antimicrobial agents. This difference is also seen in CAPP disinfection and it is reported that Gram-negative bacteria are often more susceptible to CAPP than Gram-positive. ${ }^{46-48}$ In this study, we chose as examples of a Gram-negative bacillus and a Gram-positive cocci, E. coli, and S. aureus, respectively.

In the hospital environment, bacteria are not often found in planktonic form but in biofilm structures. ${ }^{17,18,49}$ Previous research by our group carried out on a single jet, CAPP system found that the greatest reduction on a range of bacteria on common hospital surfaces occurred after $90 \mathrm{~s}$ treatment. ${ }^{37}$

E. coli and MRSA biofilms were grown on a range of surface materials often found in hospital settings. Biofilms were treated with CAPP for $90 \mathrm{~s}$ and the resulting bacterial viability was measured. The results of this assay showed that $90 \mathrm{~s} \mathrm{CAPP}$ treatment was effective in reducing bacterial viability by $30 \%$ (MRSA, powder coated steel) to $82 \%$ (E. coli, polystyrene) compared to an untreated biofilm of the same. Total eradication of the biofilm was not achieved after $90 \mathrm{~s}$ CAPP treatment. Some studies have shown eradication of clinical biofilms below detection limits after 6 minutes of plasma exposure. ${ }^{32}$ However, the aim of hospital decontamination is not the sterilization of surfaces but a significant decrease in the effective removal of the microbial load. 
We also demonstrated bacterial inactivation through confocal microscopy and staining with propidium iodide. Decreases in intact, live cells were observed after CAPP treatment. This may also suggest that CAPP may inactivate bacteria through membrane damage. CAPP treatment of bacterial biofilms was also assessed in combination with standard cleaning.

Cleaning is needed for the removal of dirt from surfaces, and any decontamination tool should be seen as an adjunct to current cleaning practices. ${ }^{11}$ The results show that a combination treatment of both cleaning solution and CAPP led to greater bacterial inactivation than either treatment alone.

This pilot study has shown the decontamination ability of a CAPP device against bacterial biofilms on hospital surfaces. However, further work should be done to assess the effectiveness of CAPP devices for hospital surface decontamination. This study examined only 2 bacterial strains and mono-species biofilms. Future works should examine mixed-culture biofilms on hospital surfaces, as well as the effect of biological soil or dirt on surfaces, which can often impede decontamination processes. ${ }^{14,50}$ Ultimately, after further in vitro studies are done, CAPP should be brought directly to the clinical environment and its efficacy and affect assessed there.

\section{CONCLUSIONS}

CAPP has been shown to inactivate clinically relevant bacteria both in planktonic state and within the protective biofilm structure. As such, CAPP devices may have potential as a decontamination tool. However, it is important to think of decontamination devices, such as CAPP, as an adjunct to hospital cleaning rather than relying on them alone. In conjunction with routine hospital cleaning, the use of CAPP devices may be of use to reduce microbial contamination on surfaces and the increased decontamination power may be useful in the prevention of HAIs.

\section{REFERENCES}

1. Thampi N, Showler A, Burry L, Bai AD, Steinberg M, Ricciuto DR, Bell CM, Morris AM. Multicenter study of health care cost of patients admitted to hospital with Staphylococcus aureus bacteremia: Impact of length of stay and intensity of care. Am J Infect Control. 2015;43(7):739-44. doi: 10.1016/j. ajic.2015.01.031.

2. Manoukian S, Stewart S, Dancer S, Graves N, Mason H, McFarland A, Robertson C, Reilly J. Estimating excess length of stay due to healthcare-associated infections: A systematic review and meta-analysis of statistical methodology. J Hosp Infect. 2018;100(2):222-35. doi: 10.1016/j.jhin.2018.06.003.

3. The European Centre for Disease Prevention and Control. Point prevalence survey of healthcareassociated infections and antimicrobial use in European acute care hospitals - ECDC PPS validation protocol version 3.1.2., (n.d.). Available from: https:/www.ecdc.europa.eu/en/publications-data/ point-prevalence-survey-healthcare-associated-infections-and-antimicrobial-use-4\#copy-to-clipboard (accessed March 23, 2020).

4. Dancer SJ. Controlling hospital-acquired infection: Focus on the role of the environment and new technologies for decontamination. Clin Microbiol Rev. 2014;27(4):665-90. doi: 10.1128/cmr.00020-14.

5. Rutala WA, Kanamori H, Gergen MF, Knelson LP, Sickbert-Bennett EE, Chen LF, Anderson DJ,

Volume 11, Issue 1, 2021 
Sexton DJ, Weber DJ. Enhanced disinfection leads to reduction of microbial contamination and a decrease in patient colonization and infection. Infect Control Hosp Epidemiol. 2018;39(9):1118-21. doi: $10.1017 /$ ice.2018.165.

6. Dancer SJ, White LF, Lamb J, Girvan EK, Robertson C. Measuring the effect of enhanced cleaning in a UK hospital: A prospective cross-over study. BMC Med. 2009;7:28. doi: 10.1186/ 1741-7015-7-28.

7. Wojgani H, Kehsa C, Cloutman-Green E, Gray C, Gant V, Klein N. Hospital door handle design and their contamination with bacteria: a real life observational study. Are we pulling against closed doors? PLoS One. 2012;7(10):e40171. doi: 10.1371/journal.pone.0040171.

8. Jinadatha C, Villamaria FC, Coppin JD, Dale CR, Williams MD, Whitworth R, Stibich M. Interaction of healthcare worker hands and portable medical equipment: A sequence analysis to show potential transmission opportunities. BMC Infect Dis. 2017;17(1):800. doi: 10.1186/s12879-017-2895-6.

9. Adams CE, Smith J, Watson V, Robertson C, Dancer SJ. Examining the association between surface bioburden and frequently touched sites in intensive care. J Hosp Infect. 2017;95(1):76-80. doi: 10.1016/j.jhin.2016.11.002.

10. McDermott H, Skally M, O'Rourke, J, Humphreys H, Fitzgerald-Hughes D. Near-patient environmental contamination of an intensive care unit with Vancomycin-resistant Enterococci (VRE) and extended-spectrum beta-lactamase-producing Enterobacteriaceae (ESBL-E) before and after the introduction of chlorhexidine bathing for patients. Infect Control Hosp Epidemiol. 2018;39(9):1131-2. doi: 10.1017/ice.2018.146.

11. Dancer SJ. Dos and don'ts for hospital cleaning. Curr Opin Infect Dis. 2016;29(4):415-23. doi: 10.1097/QCO.0000000000000289.

12. Shimoda T, Okubo T, Enoeda Y, Yano R, Nakamura S, Thapa J, Yamaguchi H. Effect of thermal control of dry fomites on regulating the survival of human pathogenic bacteria responsible for nosocomial infections. PLoS One. 2019;14(12):e0226952. doi: 10.1371/journal.pone.0226952.

13. Kramer A, Schwebke I, Kampf G. How long do nosocomial pathogens persist on inanimate surfaces? A systematic review. BMC Infect Dis. 2006;6:130. doi: 10.1186/1471-2334-6-130.

14. Esteves DC, Pereira VC, Souza JM, Keller R, Simões RD, Winkelstroter Eller LK, Rodrigues MVP. Influence of biological fluids in bacterial viability on different hospital surfaces and fomites. Am J Infect Control. 2016;44(3):311-4. doi: 10.1016/j.ajic.2015.09.033.

15. Mah TF, O'Toole GA. Mechanisms of biofilm resistance to antimicrobial agents. Trends Microbiol. 2001;9(1):34-9. doi: 10.1016/s0966-842x(00)01913-2.

16. Almatroudi A, Gosbell IB, Hu H, Jensen SO, Espedido BA, Tahir S, Glasbey TO, Legge P, Whiteley G, Deva A, Vickery K. Staphylococcus aureus dry-surface biofilms are not killed by sodium hypochlorite: Implications for infection control. J Hosp Infect. 2016;93(3):263-70. doi: 10.1016/j. jhin.2016.03.020.

17. Hu H, Johani K, Gosbell IB, Jacombs ASW, Almatroudi A, Whiteley GS, Deva AK, Jensen S, Vickery $\mathrm{K}$. Intensive care unit environmental surfaces are contaminated by multidrug-resistant bacteria in biofilms: Combined results of conventional culture, pyrosequencing, scanning electron microscopy, and confocal laser microscopy. J Hosp Infect. 2015;91(1):35-44. doi: 10.1016/j.jhin.2015.05.016.

18. Ledwoch K, Dancer SJ, Otter JA, Kerr K, Roposte D, Rushton L, Weiser R, Mahenthiralingam E, Muir DD, Maillard JY. Beware biofilm! Dry biofilms containing bacterial pathogens on multiple healthcare surfaces; a multi-centre study. J Hosp Infect. 2018;100(3):e47-e56. doi: 10.1016/j.jhin.2018.06.028.

19. Weber DJ, Kanamori H, Rutala WA. "No touch" technologies for environmental decontamination: Focus on ultraviolet devices and hydrogen peroxide systems. Curr Opin Infect Dis. 2016;29(4):42431. doi: 10.1097/QCO.0000000000000284.

20. Weber DJ, Rutala WA, Anderson DJ, Chen LF, Sickbert-Bennett EE, Boyce JM. Effectiveness of ultraviolet devices and hydrogen peroxide systems for terminal room decontamination: Focus on clinical trials. Am J Infect Control. 2016;44(5 Suppl):e77-84. doi: 10.1016/j.ajic.2015.11.015.

21. Lu H, Patil S, Keener KM, Cullen PJ, Bourke P. Bacterial inactivation by high-voltage atmospheric 
cold plasma: Influence of process parameters and effects on cell leakage and DNA. J Appl Microbiol. 2014;116(4):784-94. doi: 10.1111/jam.12426.

22. Suwal S, Coronel-Aguilera CP, Auer J, Applegate B, Garner AL, Huang JY. Mechanism characterization of bacterial inactivation of atmospheric air plasma gas and activated water using bioluminescence technology. Innov Food Sci Emerg Technol. 2019;53:18-25. doi: 10.1016/j.ifset.2018.01.007.

23. Perni S, Liu DW, Shama G, Kong MG. Cold atmospheric plasma decontamination of the pericarps of fruit. J Food Prot. 2008;71(2):302-8. doi: 10.4315/0362-028X-71.2.302.

24. Brun P, Bernabè G, Marchiori C, Scarpa M, Zuin M, Cavazzana R, Zaniol B, Martines E. Antibacterial efficacy and mechanisms of action of low power atmospheric pressure cold plasma: Membrane permeability, biofilm penetration and antimicrobial sensitization. J Appl Microbiol. 2018;125(2):398-408. doi: 10.1111 /jam. 13780 .

25. Imlay JA. The molecular mechanisms and physiological consequences of oxidative stress: Lessons from a model bacterium. Nat Rev Microbiol. 2013;11(7):443-54. doi: 10.1038/nrmicro3032.

26. Slauch JM. How does the oxidative burst of macrophages kill bacteria? Still an open question. Mol Microbiol. 2011;80(3):580-3. doi: 10.1111/j.1365-2958.2011.07612.x.

27. Dedon PC, Tannenbaum SR. Reactive nitrogen species in the chemical biology of inflammation. Arch Biochem Biophys. 2004;423(1):12-22. doi: 10.1016/j.abb.2003.12.017.

28. Laroussi M. Cold plasma in medicine and healthcare: The new frontier in low temperature plasma applications. Front Phys. 2020;8:74. doi: 10.3389/fphy.2020.00074.

29. Sun Y, Yu S, Sun P, Wu H, Zhu W, Liu W, Zhang J, Fang J, Li R. Inactivation of Candida biofilms by non-thermal plasma and its enhancement for fungistatic effect of antifungal drugs. PLoS One. 2012;7(7):e40629. doi: 10.1371/journal.pone.0040629.

30. Delben JA, Zago CE, Tyhovych N, Duarte S, Vergani CE. Effect of atmospheric-pressure cold plasma on pathogenic oral biofilms and in vitro reconstituted oral epithelium. PLoS One. 2016;11(5):e0155427. doi: 10.1371/journal.pone.0155427.

31. Puligundla P, Mok C, Pradeep P, Chulkyoon M. Non-thermal plasmas (NTPs) for inactivation of viruses in abiotic environment. 2016. Available from: https://www.researchgate.net/publication/304639945 (accessed June 25, 2020).

32. Flynn PB, Higginbotham S, Alshraiedeh NH, Gorman SP, Graham WG, Gilmore BF. Bactericidal efficacy of atmospheric pressure non-thermal plasma (APNTP) against the ESKAPE pathogens. Int J Antimicrob Agents. 2015;46(1):101-7. doi: 10.1016/j.ijantimicag.2015.02.026.

33. Niemira BA, Boyd G, Sites J. Cold plasma inactivation of Escherichia coli O157:H7 biofilms. Front Sustain Food Syst. 2018;2:47. doi: 10.3389/fsufs.2018.00047.

34. O’Connor N, Cahill O, Daniels S, Galvin S, Humphreys H. Cold atmospheric pressure plasma and decontamination. Can it contribute to preventing hospital-acquired infections? J Hosp Infect. 2014;88(2):59-65. doi: 10.1016/j.jhin.2014.06.015.

35. Bekeschus S, Favia P, Robert E, von Woedtke T. White paper on plasma for medicine and hygiene: Future in plasma health sciences. Plasma Process Polym. 2019;16(1):1800033. doi: 10.1002/ ppap.201800033.

36. Gilmore BF, Flynn PB, O’Brien S, Hickok N, Freeman T, Bourke P. Cold plasmas for biofilm control: Opportunities and challenges. Trends Biotechnol. 2018;36(6):627-38. doi: 10.1016/j. tibtech.2018.03.007.

37. Cahill OJ, Claro T, O'Connor N, Cafolla AA, Stevens NT, Daniels S, Humphreys H. Cold air plasma to decontaminate inanimate surfaces of the hospital environment. Appl Environ Microbiol. 2014;80(6):2004-10. doi: 10.1128/aem.03480-13.

38. Otter JA, Vickery K, Walker JT, deLancey Pulcini E, Stoodley P, Goldenberg SD, Salkeld JA, Chewins J, Yezli S, Edgeworth JD. Surface-attached cells, biofilms and biocide susceptibility: Implications for hospital cleaning and disinfection. J Hosp Infect. 2015;89(1):16-27. doi: 10.1016/j. jhin.2014.09.008.

39. Peters A, Otter J, Moldovan A, Parneix P, Voss A, Pittet D. Keeping hospitals clean and safe without 
breaking the bank; summary of the healthcare cleaning forum 2018. Antimicrob Resist Infect Control. 2018;7:132. doi: 10.1186/s13756-018-0420-3.

40. Edelblute CM, Malik MA, Heller LC. Surface-dependent inactivation of model microorganisms with shielded sliding plasma discharges and applied air flow. Bioelectrochemistry. 2015;103:22-7. doi: 10.1016/j.bioelechem.2014.08.013.

41. Sharma M, Hudson JB. Ozone gas is an effective and practical antibacterial agent. Am J Infect Control. 2008;36(8):559-63. doi: 10.1016/j.ajic.2007.10.021.

42. Health and Safety Executive. EH40/2005 workplace exposure limits. 4th ed. London: The Stationery Office; 2007.

43. Dancer SJ, Kramer A. Four steps to clean hospitals: LOOK, PLAN, CLEAN and DRY. J Hosp Infect. 2019;103(1):e1-e8. doi: 10.1016/j.jhin.2018.12.015.

44. Mahasneh A, Darby M, Tolle SL, Hynes W, Laroussi M, Karakas E. Inactivation of Porphyromonas gingivalis by low-temperature atmospheric pressure plasma. Plasma Med. 2011;1(3-4):191-204.

45. Russell AD. Mechanisms of bacterial insusceptibility to biocides. Am J Infect Control. 2001;29(4):25961. doi: 10.1067/mic.2001.115671.

46. Han L, Patil S, Boehm D, Milosavljevic V, Cullen PJ, Bourke P. Mechanisms of inactivation by highvoltage atmospheric cold plasma differ for Escherichia coli and Staphylococcus aureus. Appl Env Microbiol.2016;82(2):450-8. doi: 10.1128/aem.02660-15.

47. Mai-Prochnow A, Clauson M, Hong J, Murphy AB. Gram positive and Gram negative bacteria differ in their sensitivity to cold plasma. Sci Rep. 2016;6:38610. doi: 10.1038/srep38610.

48. Mai-Prochnow A, Murphy AB, McLean KM, Kong MG, Ostrikov K. Atmospheric pressure plasmas: Infection control and bacterial responses. Int J Antimicrob Agents. 2014;43(6):508-17. doi: 10.1016/j. ijantimicag.2014.01.025.

49. Farias PG, Gama F, Reis D, Alarico S, Empadinhas N, Martins JC, de Almeida AF, Morais PV. Hospital microbial surface colonization revealed during monitoring of Klebsiella spp., Pseudomonas aeruginosa, and non-tuberculous mycobacteria. Antonie Van Leeuwenhoek. 2017;110(7):863-76. doi: 10.1007/s10482-017-0857-z.

50. Chowdhury D, Rahman A, Hu H, Jensen SO, Deva AK, Vickery K. Effect of disinfectant formulation and organic soil on the efficacy of oxidizing disinfectants against biofilms. J Hosp Infect. 2019;103(1):e33-e41. doi: 10.1016/j.jhin.2018.10.019. 